\title{
The Correlates and Gender Differences of Sexual Behavior of Single Young Adults in Thailand
}

\author{
Theodore D. Fuller ${ }^{1}$, Aphichat Chamratrithirong${ }^{2}$ \& Kanya Apipornchaisakul ${ }^{3}$
}

Using a nationally-representative sample of single young adults from the National Sexual Behavior Study of Thailand $(N=1,852)$, we explore individual-, family-, peer-, and community-level factors related to premarital sex. Over $50 \%$ of single young males and about $20 \%$ of single young females aged 18-24 in Thailand report having engaged in sexual activity the past 12 months. Better education and frequent consumption of alcohol increases the likelihood of premarital sex. The incidence of sex is higher among working men than women. Young adults perceive that parents are more tolerant with promiscuity among their sons rather than daughters. The attitudes of fathers seem particularly important. When parents are more aware of the activities of young adult children, the latter are less likely to be sexually promiscuous, which however also appear to be affected by urbanity. The sexual experience of close friends is closely related to the sexual activity of the focal young adults.

Keywords Premarital sex; peer influence; young adults; parental knowledge; gender differences

Sexual behavior among adolescents and young adults has been a matter of considerable interest for academics and parents.

Although premarital sex is more common in more developed countries, evidence indicates sexual activity among young adults is also on the rise in various less developed countries (Singh et al. 2000:275-300), including Thailand (Lyttleton 1999, Tangmunkongvorakul, Kane and Wellings 2005, Thianthai 2004).

In Thailand, the risk of transmission of sexually transmitted diseases, including HIV/AIDS, among young adults is aggravated by the reluctance of many parents to speak to their children about contraceptives (Rhuchareonpornpanich et al. 2012, Sridawruang, Crozier and Pfeil 2010, Sridawruang, Pfeil and Crozier 2010). While pregnancy among unmarried women in the Western nations no longer carries the stigma it once did, in Thailand it may bring shame on the family (UNFPA 2013). Thus although abortion is illegal and viewed as a serious moral transgression in Thailand (UNFPA 2013, Whittaker 2004), estimates indicate there may be 200,000-300,000 abortions in the country annually (Tangcharoensathien, Chaturachinda and Im-em 2015); almost half of induced abortions by women under the age of 25 (Warakamin, Boonthai and Tangcharoensathien 2004). A further risk of intimate relationships among the unmarried is the risk of dating violence (Thongpriwan and McElmurry 2009). This risk may be greater for unmarried women who are in a relationship that has progressed to sexual

\footnotetext{
${ }^{1}$ Department of Sociology, Virginia Tech, Blacksburg VA 24061 USA. Email: ted.fuller@vt.edu

2 Institute for Population and Special Research, Mahidol University, Nakhon Pathom, Thailand.

Email: aphichat.cha@mahidol.ac.th

${ }^{3}$ Institute for Population and Special Research, Mahidol University, Nakhon Pathom, Thailand.

Email: kanya.app@mahidol.ac.th
} 
intimacy. This paper focuses on the factors and risks associated with single young adults engaging in sexual behavior.

We use a social ecology model developed by Blum and colleagues to organize our discussion and study individual, family, peer, and community factors related to sexual behavior among single young adults. Bronfenbrenner (Bronfenbrenner 1979, Bronfenbrenner 1989), Jessor (Jessor 1991), and others, Blum and colleagues (Blum, McNeely and Nonnemaker 2002) posit that six domains - individual, family, peers, school, immediate social environment, and macro level environments - impact risk behavior.

There is a large literature on the factors affecting premarital sexual activity.

Globally, one key risk factor is gender. In many countries, males begin to engage in sex at an earlier age than females. Gender is important because premarital sexual debut is often more problematic and more controversial for women. A sexual double standard is found in many countries, and Thailand is no exception (Knodel et al. 1996, Knodel et al. 1999, Thianthai 2004, VanLandingham and Grandjean 1997). Traditional Thai social norms encourage men to have multiple sexual partners while women are to remain virgins until marriage (Thienthai 2004).

In many cultures, the consumption of alcohol is related to greater sexual promiscuity (Anderson and Mueller 2008). Generally in Thailand, men tend to drink larger amounts of alcohol frequently which in turn leads to active sex life (Fordham 1995, MacQueen et al. 1996, VanLandingham and Grandjean 1997), but the relationship between alcohol and noncommercial premarital sex has yet to be examined. We hypothesize that greater alcohol consumption among single young adult drinks alcohol there will be more sex.

Regardless of religion, a young person's religiosity is likely to restrain decisions about sexual activity (Burdette and Hill 2009, Chamratrithirong et al. 2010). It is worth noting that a recent study in Bangkok found that the parent's religiosity was a significant predictor of the extent of parent-child communication on sex (Rhucharoenpornpanich et al. 2012).

The family is obviously a vital social context for socialization and social control of children, even into young adulthood (Meschke, Bartholomae and Zentall 2002, Miller, Benson and Galbraith 2001). The values that parents express, such as approval or disapproval of premarital sex, can influence the child's decision to engage in premarital sex (Jaccard and Kittus 2000). Parental knowledge of their children's whereabouts and activities can result from various processes (i.e., parent initiated or child initiated) (Bumpus and Rodgers 2009, Stattin and Kerr 2000 ), but greater parental knowledge tends to be associated with less involvement in risky behavior. Specifically, we hypothesize that the more parents know the whereabouts and activities of their single young adult child, the less likely that child will be engaging in sexual intercourse; the more of the single young adult child's close friends the parent knows, the less likely the child is to have sex; and if the young adult child perceives that their mother and/or father finds it unacceptable for them to engage in premarital sex, it is less likely that the young adult child will be having sexual intercourse. Furthermore, the young adult's living arrangements can be a risk factor for sexual activity. We hypothesize that a young adult living with both parents is less likely to be involved in sexual intercourse compared to a young adult living with one parent or neither parent.

An adolescent or young person's peers can influence the focal person's behavior. Research suggests that if the young person's peers are actively engaged in sexual intercourse the focal person would want to do so too (Ali and Dwyer 2011, Kinsman et al. 1998, Maxwell 2002, VanLandingham and Grandjean 1997). We therefore hypothesize that the greater the number of a young person's friends are sexually promiscuous it is likely they too will be similarly inclined. 
Previous research indicates that engaging in premarital sexual intercourse is more common in urban areas (Podhisita, Xenos and Varangrat 2001, Podhisita 2009, VanLandingham et al. 1993). Furthermore, a recent analysis indicated that, for both male and female never-married young adults, rural-urban migration is associated with greater exposure to become engaged in premarital sexual intercourse (Phuengsamran, Chamratrithirong, Guest, \& VanLandingham, 2014). We hypothesize that young adults living in Bangkok are most likely to be active involved in sexual intercourse than those living in other urban or rural areas.

\section{Method}

\section{Data source}

The data used in this paper is from the National Sexual Behavior Study of Thailand, 2006, based on a multi-stage probability sample. The sample was stratified by residence (Bangkok, other urban, and rural), age (18-24, 25-59), and sex. In addition to Bangkok, data were collected from urban and rural areas in 14 provinces in Thailand. These 14 provinces were sampled from the 75 provinces in Thailand with probability proportional to the size of the population of each province. Within Bangkok and the 14 provinces, districts were sampled using probability methods. Households were randomly sampled from sample districts in Bangkok and in the urban and rural areas of the other 14 provinces. Eligible household members (meeting the age and sex requirements) in Bangkok and the 14 provinces were then interviewed by a same-sex interviewer. The sample was designed to have the same number of respondents selected from each of 12 strata -- defined by three residence types, two genders, and two age groups -- for a total of 6048 respondents. When properly weighted, the sample provides nationally representative estimates. Full details are available in Chamratrithirong et al. (2007). The target population for this paper is single young adults age 18-24 who are neither married nor cohabiting $(\mathrm{n}=1862)$, are known as "single young adults".

\section{Variables}

Two key outcome variables are used. We briefly report results to the question "Have you ever had sexual intercourse?" but focus the analysis on the question "Have you engaged in sexual intercourse during the past 12 months?"

Two key predictor variables are gender and age. Age is coded in individual years of age.

In addition to gender and age, the following individual-level variables are used in models predicting whether single young adults engaged in sexual intercourse in the past 12 months: level of educational attainment, current work status, frequency of use of alcohol, and religiosity.

Work status is based on the question "Are you currently studying or working, or both?" collapsed into two categories (working, not working).

Although some young adults in Thailand are still studying most are not. Educational attainment is an ordinal variable with seven levels, ranging from no formal education to having a four-year college degree.

Frequency of alcohol consumption was assessed with the question "Usually, how often do you drink alcoholic drinks?"

We did not hypothesize that religion would be related to sexual behavior, but respondents were asked "What is your religion?" 
Religiosity is determined by asking "How would you describe your religious life?" with responses ranging from $1=$ not very religious to $4=$ very religious. All three religions represented in our sample - Buddhism, Islam, and Christianity -- discourage premarital sex (Adamczyk and Hayes 2014). We hypothesize that greater religiosity will be negatively related to engaging in sex.

The following family-level variables are used in the analysis: parental knowledge, parental attitudes, and living arrangements.

Two items measure parental knowledge. First, "Generally, in each day do your parents/guardians know where you are, who you are with, or what you are doing?" (Five response categories, ranging from $1=$ never to 5 =always). The second question is "Do your parents/guardians know your close friends?" (Five response categories ranging from 1=not at all to $5=$ know all of them.)

Respondents were also asked the following four questions to measure the young adult's perception of their parent's views on premarital sex: "To the best of your knowledge, do you think your [father or male guardian] thinks that premarital sex is acceptable for his [son/daughter]" and "To the best of your knowledge, do you think your [mother or female guardian] thinks that premarital sex is acceptable for her [son/daughter]?" The young adult's perceptions of their parents' views on this subject are presumably a function of whether the parents communicated this to their child and the emphasis with which they communicated their views. The vast majority of respondents answered "yes" or "no", but some said "don't know" or "not sure". From a theoretical standpoint, it is important to know whether a parent clearly communicated disapproval of premarital sex. If the young adult responded "don't know" or "not sure", we infer the parent did not clearly communicate disapproval of premarital sex. Therefore, we combine the "don't know" and "not sure" responses with the "yes" responses.

In the descriptive analysis, we report all four variables pertaining to parents' attitudes regarding premarital sex. In the multivariate analysis, however, we recode these variables. There is no clear theoretical reason to expect that a son's perception of parental attitudes would have any effect on his likelihood to engaging in sexual intercourse (or that a daughter's perception of parental attitudes about her young single brother engaging in sex would affect her likelihood of engaging in sex). Furthermore, there is a strong correspondence between the father's and mother's view on the appropriateness for a young single adult to engage in sex (for sons, the correlation is .75; for daughters, .72). Accordingly, we recode "father's attitude" such that it reflects the father's attitude towards a child of the same gender as that of the respondent's own; similarly, the recoded "mother's attitude" reflects the mother's attitude towards a child of the gender as that of the respondent's own.

Living arrangement is coded as two dummy variables: (a) the young adult is living with both parents $(1=$ yes, $0=$ no $)$ and (b) the young adult is living with one parent $(1=y e s, 0=$ no).

Two peer-level variables are used in the analysis, based on the following questions: "How would you describe the sexual experience of your close male friends?" and "How would you describe the sexual experience of your close female friends?" (Five responses, ranging from $1=$ none have sexual experience to $5=$ all have sexual experience.) These questions tap perceptions of their friends' behavior rather than their friends' actual behavior. The Thomas theorem and a number of empirical research (Cvetkovich and Grote 1980) suggest, the focal person's perceptions of their peers' behavior is likely influences their own behavior even more than the actual behavior of their peers. 
As indicated above, three types of communities are distinguished in this study: Bangkok, other urban areas, and rural areas.

\section{Analysis plan}

After a review of the similarities and differences between single young men and women in Thailand in terms of the key variables used in this study a series of multivariate analyses was conducted. First, the effect of each block separately, i.e., individual variables, then family variables, second, peer variables, and finally community variables were examined. Second, each block was sequentially examined, beginning with the individual variables and ending with the community variables. Finally, we consider interaction effects involving sex. Inasmuch as our main dependent variable is a dichotomy, we use logistic regression.

\section{Results}

In Thailand as a whole, there are roughly the same number of men and women in the age group 18-24. Among the single young adults In the case of our sample the ratio was 63males to 37 females.

\section{Respondent characteristics}

Single young men age 18-24 are more likely to report to have had sex $(72 \%)$ with $57 \%$ having had sex in the past 12 months. This suggests that it may not be warranted to assume that single young men who "ever" had sex continue to do so on a regular basis. The comparable figures for single young women age $18-24$ are $22 \%$ and $20 \%$. Apparently most young women who initiate sex continue to have sex. See Table 1. As noted above, there is a "sexual double standard" in Thailand, such that under reporting among females takes place.

Table 1: Variable distribution by gender

\begin{tabular}{lrrr}
\hline \multicolumn{1}{c}{ Variable } & Males & Females & Significance \\
\hline Number of cases & & & \\
$\quad$ unweighted & 1169 & 683 & .001 \\
Had sex in past 12 months (\% yes) & $57.1 \%$ & $19.8 \%$ & .01 \\
Age (mean) & 20.6 & 20.3 & .001 \\
Education & $16.6 \%$ & $8.1 \%$ & \\
$\quad$ Less than Junior High School & $37.8 \%$ & $26.5 \%$ & \\
$\quad$ Junior High School & $35.1 \%$ & $47.1 \%$ & \\
$\quad$ Senior High School & $10.5 \%$ & $18.3 \%$ & \\
Beyond Senior High School & & & .001 \\
& 3.4 & 3.8 & .001 \\
Mean & $56.5 \%$ & $32.7 \%$ & .001 \\
Currently working (percent) & & & \\
Frequency of alcohol consumption & $13.7 \%$ & $52.0 \%$ & \\
$\quad$ Never drink alcohol & $18.9 \%$ & $34.4 \%$ & \\
Once in many months & $19.1 \%$ & $9.2 \%$ & \\
1 or 2 times a month & $19.9 \%$ & $2.8 \%$ & \\
1 or 2 times a week & $21.0 \%$ & $1.2 \%$ & \\
$\quad$ More than 2 times a week & $7.4 \%$ & $0.4 \%$ & \\
Every day & & & \\
$\quad$ Mean & 3.4 & 1.7 & .001 \\
\hline
\end{tabular}




\begin{tabular}{|c|c|c|c|}
\hline Variable & Males & Females & Significance \\
\hline \multicolumn{4}{|l|}{ Religion } \\
\hline Buddhist & $95.7 \%$ & $96.0 \%$ & \multirow[t]{3}{*}{ ns } \\
\hline Muslim & $2.7 \%$ & $3.5 \%$ & \\
\hline Christian & $1.5 \%$ & $0.4 \%$ & \\
\hline Religiosity (mean) & 2.5 & 2.6 & .001 \\
\hline \multicolumn{4}{|l|}{ Parental knowledge } \\
\hline Parents know activities & 3.2 & 4.2 & .001 \\
\hline Parents know friends & 3.6 & 4.0 & .001 \\
\hline \multicolumn{4}{|c|}{ Parental attitude about premarital sex for son/daughter: } \\
\hline Father: Acceptable for son & $88.3 \%$ & $64.7 \%$ & \multirow[t]{2}{*}{.001} \\
\hline Father: Not acceptable for son & $11.7 \%$ & $35.3 \%$ & \\
\hline Father: Acceptable for daughter & $34.7 \%$ & $25.8 \%$ & \multirow[t]{2}{*}{.001} \\
\hline Father: Not acceptable for daughter & $65.3 \%$ & $74.2 \%$ & \\
\hline Mother: Acceptable for son & $84.0 \%$ & $61.2 \%$ & \multirow[t]{2}{*}{.001} \\
\hline Mother: Not acceptable for son & $16.0 \%$ & $38.8 \%$ & \\
\hline Mother: Acceptable for daughter & $29.2 \%$ & $23.4 \%$ & \multirow[t]{2}{*}{.01} \\
\hline Mother: Not acceptable for daughter & $70.8 \%$ & $76.6 \%$ & \\
\hline \multicolumn{4}{|l|}{ Living arrangements } \\
\hline With both parents & $60.0 \%$ & $58.7 \%$ & \multirow[t]{3}{*}{ ns } \\
\hline With one parent & $15.9 \%$ & $14.3 \%$ & \\
\hline Not with either parent & $24.1 \%$ & $27.0 \%$ & \\
\hline \multicolumn{4}{|l|}{ Sexual experience of close friends } \\
\hline Males (mean for cases with data) & 3.84 & 3.81 & ns \\
\hline Females (mean for cases with data) & 3.24 & 3.03 & .001 \\
\hline Males - percent missing data & $3.8 \%$ & $14.9 \%$ & .001 \\
\hline Females - percent missing data & $17.9 \%$ & $6.7 \%$ & .001 \\
\hline \multicolumn{4}{|l|}{ Residence } \\
\hline Bangkok & $11.0 \%$ & $16.5 \%$ & .001 \\
\hline Other urban & $29.5 \%$ & $35.1 \%$ & \\
\hline Rural & $59.5 \%$ & $48.3 \%$ & \\
\hline
\end{tabular}

Weighted results are presented

As indicated above, key variables were organized in terms of social ecological levels: individual, family, peer, and community variables. Before analyzing how these variables are related to sexual activity, we discuss them in the context of gender.

The mean age for young single women (20.3 years) is slightly less than that of young single men (20.6 years) (Table 1$)$.

Young single women tend to be better educated than young single men. For example, about $47 \%$ of young single women completed senior high school, compared to about $35 \%$ of young single men, and an additional $18 \%$ of young single women have an education beyond high school, compared to about $11 \%$ for young single men.

Slightly more than half of single young men are working, compared to $33 \%$ of women.

Single young men drink more frequently than single young women. About $28 \%$ of single young men report that they drink alcohol more than twice a week or even daily, compared to 
about $2 \%$ of women. Conversely, a majority of women (52\%) said they never drink alcohol, compared to only $14 \%$ of men.

Compared to young single men, young single women report a significantly higher level of religiosity, but the difference is very small.

In terms of family-level variables, single young women are significantly more likely than single young men to report that, in general, their parents know their whereabouts (4.2 for women versus 3.2 for men). Women are also significantly more likely to report that their parents know their close friends, but the difference between women and men is not large (4.0 for women versus 3.6 for men). These results are consistent with other research on parental monitoring of their $r$ daughters and sons (Chamratrithirong et al. 2010).

Majority of single young men and women indicate their parents' consent to sons being sexually promiscuous, evidently pointing to a sexual double standard.

$60 \%$ live with both of their biological parents; another 14\%-16\% live with one parent.

Both single young males and females believe that their close male friends are more likely to engage in sex than their close female friends.

A somewhat large percent of single women live in Bangkok and other urban areas. Single women are somewhat less likely to live in rural areas. These differences reflect the tendency of rural women to marry at somewhat younger ages, compared to urban women. Once they marry, they are no longer in our target population.

We now turn to the question of who is more likely to engage in sexual relations.

\section{Premarital sex: multivariate relationships}

\section{Analyses of each block separately}

The initial block includes only individual-level factors. Single young adult women are far less likely to engage in sexual activity than their male counterparts (Table 2, Model 1, odds ratio = .293). Also, single young adults with more education are more likely to engage in sex, compared to peers with less education, and, single young adults who consume alcohol more frequently are more likely to engage in sexual activity. However, working status and religiosity are not significantly related to the likelihood of engaging in sex.

Table 2: Predictors of having sex in the last 12 months: Odds ratios from multivariate logistic regression, with each separate social ecological level

\begin{tabular}{lcccc}
\hline \multicolumn{1}{c}{ Predictor } & Model 1 & Model 2 & Model 3 & Model 4 \\
\hline Intercept & $.131^{* * *}$ & .958 & $.041^{* * *}$ & .042 \\
Individual factors & & & & \\
Sex (male is reference) & $.293^{* * *}$ & $.457^{* * *}$ & $.157^{* * *}$ & $.170^{* * *}$ \\
Age (in years) & 1.064 & & & \\
Education (in years) & $1.161^{*}$ & & \\
Work status (working is reference) & .806 & & \\
Frequency of alcohol consumption & $1.343^{* * *}$ & & \\
Religiosity & .865 & & \\
Family factors & & & \\
Parents know activities & & $.728^{* * *}$ & \\
Parents know friends & & 1.082 & \\
Father's attitude about single adults having sex & & $2.407^{* * *}$ & \\
Mother's attitude about single adults having sex & & 1.349 &
\end{tabular}




\begin{tabular}{lcccc}
\hline \multicolumn{1}{c}{ Predictor } & Model 1 & Model 2 & Model 3 & Model 4 \\
\hline $\begin{array}{l}\text { Living with both parents (not living with either parent is } \\
\text { reference) }\end{array}$ & & 1.158 & & \\
$\begin{array}{l}\text { Living with one parent (not living with either parent is } \\
\text { reference) }\end{array}$ & & 1.005 & \\
$\begin{array}{l}\text { Peer factors } \\
\text { Sexual experience of close male friends }\end{array}$ & & $1.716^{* * *}$ & \\
$\begin{array}{l}\text { Sexual experience of close female friends } \\
\text { Community of residence }\end{array}$ & & & $1.572^{* * *}$ & \\
$\begin{array}{l}\text { Other urban (lives in Bangkok is the reference) } \\
\text { Rural area (lives in Bangkok is the reference) }\end{array}$ & & & $.699^{*}$ \\
Pseudo R-squared & .174 & .186 & .231 & .141 \\
\hline
\end{tabular}

It may be surprising that age is not significantly related to sexual promiscuity. In an analysis that includes just age and sex (not shown), both variables are significant. Males and older single young adults are more likely to engage in sex. However, when all six individual-level variables are included, age is not significantly related to sexual promiscuity.

The second block (Model 2) includes the family-level variables and gender. The results indicate that when parents know more about the young person's activities, the young person is less likely to engage in sex. Also, when the father fails to communicate disapproval, the young adult is far more likely to engage in sex (odds ratio $=2.407$ ). However, the mother's attitude is not significantly related to the likelihood that a young adult will engage in sex. However, whether the parents know the young person's friends and whether the young person lives with both parents, one parent, or neither parent is not significantly related to whether the young person engages in sex.

The third block (Model 3) includes peer-level variables and gender. If the young person perceives that a large number of their close friends engage in sex, they too would behave likewise. The perceptions pertaining to close male friends and close female friends are both related to the likelihood that the young adult will engage in sex.

The fourth block (Model 4) includes the community-level variables and gender. Compared to those who live in Bangkok, single young adults who live in other urban areas are less likely to engage in sex (odds ratio $=.699$ ), while those who live in rural areas are still less likely to engage in sex (odds ratio $=.510$ ).

Interestingly, the pseudo R-squared for the peer block is actually slightly larger than the pseudo R-squared for the other blocks, even though only two peer variables (and gender) are included in the model.

\section{Analyses with blocks added sequentially}

Next, we examine the effect of adding blocks of variables sequentially. Model 1 in Table 3 is identical to Model 1 in Table 2: gender, education, and frequency of alcohol consumption are all significantly related to the likelihood of engaging in sex.

Model 2 includes the individual-level block and adds the family-level block. With the familylevel block added to the analysis, the same three individual-level variables are still significant. Furthermore, the same two parental variables -- parent's knowledge of the young adult's activities and father's attitudes - remain significant. 
Table 3: Predictors of having sex in the last 12 months: Odds ratios from multivariate logistic regression, with cumulative effects of adding social ecological levels

\begin{tabular}{|c|c|c|c|c|}
\hline Predictor & Model 1 & Model 2 & Model 3 & Model 4 \\
\hline Intercept & $.131^{* * *}$ & $.054^{* * *}$ & $.014^{* * *}$ & $.009^{* * *}$ \\
\hline \multicolumn{5}{|l|}{ Individual factors } \\
\hline Sex (male is reference) & $.293^{* \star *}$ & $.577^{*}$ & $.414^{* * *}$ & $.412^{* * *}$ \\
\hline Age (in years) & 1.064 & 1.057 & 1.009 & 1.013 \\
\hline Education & $1.161^{*}$ & $1.220^{*}$ & $1.211^{*}$ & $1.176^{*}$ \\
\hline Work status (working is reference) & .806 & .874 & .823 & .821 \\
\hline Frequency of alcohol consumption & $1.343^{* * *}$ & $1.260^{* * *}$ & $1.225^{\star * *}$ & $1.230^{* * *}$ \\
\hline Religiosity & .865 & .897 & .948 & .932 \\
\hline \multicolumn{5}{|l|}{ Family factors } \\
\hline Parents know activities & & $.750^{* * *}$ & $.769^{* * *}$ & $.758^{* * *}$ \\
\hline Parents know friends & & 1.091 & 1.049 & 1.064 \\
\hline $\begin{array}{l}\text { Father's attitude about single adults having sex (not } \\
\text { acceptable is reference) }\end{array}$ & & $2.261^{* * *}$ & $1.884^{* *}$ & $1.931^{* *}$ \\
\hline $\begin{array}{l}\text { Mother's attitude about single adults having sex (not } \\
\text { acceptable is reference) }\end{array}$ & & 1.282 & 1.248 & 1.277 \\
\hline $\begin{array}{l}\text { Living with both parents (not living with either parents is } \\
\text { reference) }\end{array}$ & & 1.186 & 1.174 & 1.020 \\
\hline $\begin{array}{l}\text { Living with one parent (not living with either parents is } \\
\text { reference) }\end{array}$ & & 1.022 & 1.007 & 0.912 \\
\hline \multicolumn{5}{|l|}{ Peer factors } \\
\hline Sexual experience of close male friends & & & $1.582^{* * *}$ & $1.542^{* * *}$ \\
\hline Sexual experience of close female friends & & & $1.535^{* * *}$ & $1.528^{* * *}$ \\
\hline \multicolumn{5}{|l|}{ Community of residence } \\
\hline Other urban (lives in Bangkok is the ref & & & & $.695^{*}$ \\
\hline Rural area (lives in Bangkok is the reference) & & & & $.542 * * *$ \\
\hline Pseudo R-squared & .174 & .213 & .278 & .284 \\
\hline
\end{tabular}

Model 3 includes the individual- and family-level blocks and adds the peer block to the analysis. The same individual-level and family-level variables are still significant. As was true when the peer block was analyzed alone, both peer-level variables (perceived sexual experience of close male and female friends) are significant.

Model 4 includes the individual-, family-, and peer-level blocks and adds the community block to the analysis. The same individual-level, family-level, and peer-level variables are significant. The residence variable (Bangkok, urban, rural) is significant in its relation with sexual activity.

Not surprisingly, when more blocks (i.e., more social ecological levels) are added to the model, the pseudo R-squared is larger. When all variables are included, the pseudo R-squared is .284, implying that nearly $30 \%$ of the variation in sexual behavior of single young adults is explained by the model.

The most important social ecological level is the peer level. This level, with only two variables, has the highest pseudo R-squared of any block (.231; Table 2). When the peer variables are added to the individual and family variables, R-squared is increased noticeably (Table 3 ).

\section{Interaction Analysis Results}

Although work was not significant in the previous analyses, the interaction of Gender by work was significant. As shown in Table 4, among males the odds ratio for work is .688 $(p<.05)$ and among females the odds ratio was 1.258 (not significant). Since "currently working" is the reference group for work, this means that males who were not currently working were less 
likely to have engaged in sex the past 12 months suggesting working males are more likely to be sexually active in the same period. One possible interpretation is that men who worked had the economic resources to engage in social activities that might lead to sex compared to those who are unemployed. Work was not significant for females. None of the other individual-level gender interaction terms were significant.

Table 4: Odds ratios for variables where a significant gender interaction is detected

\begin{tabular}{lcc}
\hline & Among males & Among females \\
\hline Individual-level variable(a) & & \\
$\quad$ Work status & $.688^{*}$ & 1.258 \\
Family-level variables $(\mathrm{b})$ & $.785^{* * *}$ & $.580^{* * *}$ \\
$\quad$ "parents know activities" & $1.207^{* *}$ & $.825^{*}$ \\
$\quad$ "parents know friends" & & \\
Peer-level variable(c) & $1.319^{* *}$ & $2.085^{* * *}$ \\
$\quad$ Sexual experience of close female friends & &
\end{tabular}

(a) Other variables in the model are: gender, age, education, frequency of alcohol consumption, religiosity.

(b) Other variables in the model are: gender, father's attitude, mother's attitude, living with both parents, living with one parent. Note: "parents know friends" is in the model when we test for the interaction involving "parents know behavior" and "parents know behavior" is in the model when we test for the interaction involving "parents know friends".

(c) Other variables in the model are: gender and sexual experience of close male friends.

Among the family-level variables, there were two significant gender interactions: "parents know activities" and "parents know friends". In the previous analyses, "parents know activities" was significant, with an odds ratio of .758 in the full model (Table 3, Model 4). In the interaction analysis, the odds ratio for "parents know activities" was .784 for males ( $p<$ $.001)$ and .580 for females $(p<.001)$. This means that when parents are aware of the activities of their single young adults, the latter tend to be less promiscuous the past 12 months, more so with females than males. However, this is a tentative conclusion, modified below.

"Parents know friends" was not significant in the previous analyses, but the gender interaction shows that it is significant for both females and males considered separately. When parents know more of the daughter's friends, the daughter is less likely to have sex (odds ratio $=.825$ ). Unexpectedly, when the parent knows more of the son's friends, the son is more likely to have sex (odds ratio $=1.207$ ). However, this too is a tentative conclusion, modified below.

One of the two peer-level variables has a significant interaction with gender. Perceptions of the percent of close female friends who were engaging in sex has a significantly stronger effect among young women (odds ratio $=2.085, p<.001$ ) than among young men (odds ratio $=1.319$, $p<.01)$.

There was no significant interaction effect involving community of residence and gender.

\section{Full Model}

Finally, we examine the full model, with multiple significant interaction variables included together with the variables from each of the four blocks. Four interaction terms were found to be significant; when all four are included, only three are significant. We therefore present a final model including only three interaction terms.

If a gender interaction term is included for a given variable, in order to detect the effect of that variable for a specific gender, that specific gender must be the reference category. This means that the final model with the interaction terms has to be run twice: once with one gender as the reference category and then with the other gender as the reference category. Thus, two 
parallel logistic regression models are analyzed, the only difference being which gender is the reference category.

Among the individual-level variables, gender is obviously strongly related to sexual activity in the past 12 months. Males are far more likely to have engaged in sex; females far less likely.

Education, work status, and frequency of alcohol consumption are significantly related to whether the single young adult had sex in the past 12 months. For education, for each 1-unit increase in education, the odds of engaging in sex increases by about 19 percent.

Table 5: Predictors of having sex in the last 12 months: Odds ratios from multivariate logistic regression models with selected interaction terms.

\begin{tabular}{|c|c|c|c|}
\hline Predictor & Males & Females & $\begin{array}{l}\text { Significant } \\
\text { interaction? }\end{array}$ \\
\hline Intercept & $.013^{* * *}$ & $.001^{* * *}$ & \\
\hline \multicolumn{4}{|l|}{ Individual factors } \\
\hline $\begin{array}{l}\text { Gender (gender at the top of the column is the reference } \\
\text { category) }\end{array}$ & $5.979^{* * *}$ & $.167^{* * *}$ & \\
\hline Age (in years) & 1.011 & 1.011 & \\
\hline Education (in years) & $1.195^{*}$ & $1.195^{*}$ & \\
\hline Work status (working is reference) & $.644^{* *}$ & $1.850^{*}$ & ** \\
\hline Frequency of alcohol consumption & $1.226^{* * *}$ & $1.226^{* * *}$ & \\
\hline Religiosity & .937 & .937 & \\
\hline \multicolumn{4}{|l|}{ Family factors } \\
\hline Parents know activities & $.765^{* * *}$ & $.765^{* * *}$ & \\
\hline Parents know friends & 1.172 & .824 & $* *$ \\
\hline Father's attitude about single adults having sex & $2.062^{* *}$ & $2.062^{* *}$ & \\
\hline Mother's attitude about single adults having sex & 1.227 & 1.227 & \\
\hline $\begin{array}{l}\text { Living with both parents (not living with either parent is } \\
\text { reference) }\end{array}$ & 1.024 & 1.024 & \\
\hline $\begin{array}{l}\text { Living with one parent (not living with either parent is } \\
\text { reference) }\end{array}$ & .945 & .945 & \\
\hline \multicolumn{4}{|l|}{ Peer factors } \\
\hline Sexual experience of close male friends & $1.571^{* * *}$ & $1.571^{* * *}$ & \\
\hline Sexual experience of close female friends & $1.337^{* *}$ & $2.023^{* * *}$ & ** \\
\hline \multicolumn{4}{|l|}{ Community of residence } \\
\hline Other urban (lives in Bangkok is the reference) & $.706^{*}$ & $.706^{*}$ & \\
\hline Rural area (lives in Bangkok is the reference) & $.549^{* * *}$ & $.549^{* * *}$ & \\
\hline Pseudo R-squared & .297 & .297 & \\
\hline
\end{tabular}

Those who consume alcohol more frequently are more likely to have had sex in the past 12 months. While men are far more likely to consume alcohol than are women, the effect of alcohol consumption on the likelihood of having engaged in sex is same for both males and females.

Among males, working is significantly related to engaging in sex in the past 12 months; among females, not working is significantly related to engaging in sex in the past 12 months. One possible interpretation is that women who are not working have more free time. However, the latter result much be interpreted cautiously, for two reasons. First, Table 4 indicates that work status is significant only for males, not for females. The difference between Table 4 and Table 5 is that Table 5 includes three gender interaction terms while Table 4 includes only one gender interaction term at a time. Thus, the significance of work status among women may be an artifact of having multiple gender interaction terms in the equation. Second, a separate analysis (not shown) with all the variables for females finds a similar odds 
ratio for work status (1.776) which however is not significant at the .05 level. These two reasons indicate the need for caution when interpreting the category of work status for young single women.

Age and religiosity are not significantly related to sexual promiscuity although the initial interaction analysis indicated that parents' knowledge of activities is strongly related to the sexual behavior of young women. The full model finds no significant difference in the effect of this variable for men and women, suggesting greater parental awareness of the activities of single young adults leads to less pre-marital sex.

Recall that Table 4 indicated that when parents know more of their daughter's friends, she is less likely to engage in sex while knowledge of their son's friends means he is more likely to engage in sex. Table 5 indicates that there is a significant gender interaction effect, but that the percent of friends that parents know does not affect the risk of sex for either sons or daughters. Because this variable does not have a significant effect for either sons or daughters, we conclude it does not have an effect.

Perceptions of the father's attitude regarding sexual promiscuity is strongly related to sexual activity among young adults. Young men and women who perceive that their father feels it is acceptable for them to engage in premarital sex are almost twice as likely to do so, compared to their peers who perceive that their father feel otherwise. However, perceptions of the mother's attitude on this topic does not influence sexual promiscuity levels.

Living with both parents, single parent, and neither parent, too does not significantly influence the likelihood of engaging in sex.

For both males and females perceptions of the number of close friends having sex will significantly influence general sexual activity, more so for females than males.

Finally, the more urban the community the young adult lives in, the more likely the individual will be actively involved in premarital sexual intercourse.

\section{Summary and Discussion}

One of the strengths of the study is that it is based on a representative national sample of Thailand, and thus provides an opportunity to learn about risk factors involved in the sexual behavior of single young adults in a non-Western nation. The carefully designed sample provides a relatively large dataset that supports multivariate analysis using a fairly large number of predictor variables drawn from a range of social ecological levels.

Seventy-two percent of single young men report having had sex and $57 \%$ report that they had the past 12 months. Figures for females are 22\% and 20\% respectively; indicating a large discrepancy between genders.

A key factor regulating premarital sex in Thailand is the parental awareness of their young adult child's activities. While parents monitor their daughter's activities much more closely than that of son's activities, awareness mitigates premarital sex.

As implied above, father's attitude toward sex is important. If the father clearly communications to his adult child that premarital sex is unacceptable, the adult child is likely to refrain from such activity. Surprisingly, the mother's attitude does not seem to be influential.

Research in Thailand clearly indicates that alcohol consumption is closely related to sexual promiscuity, although the relationship between alcohol and non-commercial premarital sex 
remains unexplored. While men consume more alcohol compared with women its effect nevertheless appears to be similar.

Peers play an important role on sexual behavior. In fact, peers are arguably the most important at the social ecological level in terms of influencing sexual behavior of single young adults in Thailand. When single young adults perceive that their male and/or female peers are engaging in premarital sex, they are likely to follow. The perceptions of the sexual behavior of close female friends seem to be even more related to whether single young women - as opposed to single young men -- engage in sex.

In the Thai context, where most single young adults age 18-24 live their parents their behavior may be influenced concerning their friends. It may not be necessary for parents to know all or even most of the child's friends in order to overcome peer influences.

Our results indicate that the risk factors that are related to the likelihood of single young adults engaging in sex are in some ways gendered but in many ways not gendered. For most of the risk factors discussed above, the effect is the same for men and women. However, working has a different effect for men and women. Employed males are more likely to be promiscuous than single young women counterparts. Also, as noted above, the perceived sexual experience of close female friends affects both men and women, but has a significantly greater effect on women.

In sum, as theorized by Blum and his colleagues, a variety of social ecological levels -individual, family, peer, and community -- influence sexual promiscuity among single young adults in Thailand.

As mentioned at the outset, the reason for investigating sexual behavior among single young adults is to analyse the various risks associated with it. Safe sex practices can mitigate these risks among sexually-active adults. Future research can explore factors related to adoption of safe sex practices among single young adults who engage in premarital sex and how to mitigate the various risks associated with premarital sex.

\section{References}

Adamczyk, A., \& Hayes, B. E. (2014). Religion and Sexual Behaviors: Understanding the Influence of Islamic Cultures and Religious Affliation for Explaining Sex Outside of Marriage. American Sociological Review, 77(5), 723-746.

Ali, M. M., \& Dwyer, D. S. (2011). Estimating Peer Effects in Sexual Behavior among Adolescents. Journal of Adolescence, 34(1), 189-190.

Anderson, J. E. \& Mueller, T. E. (2008). Trends in Sexual Risk Behavior and Unprotected Sex among High School Students, 1991-2005: The Role of Substance Use. Journal of School Health, 78(11).

Blum, R. W., McNeely, C. \& Nonnemaker, J. (2002). Vulnerability, Risk, and Protection. Journal of Adolescent Health, 31S, 28-39.

Bronfenbrenner, U. (1979). The Ecology of Human Development. Cambridge, Massachusetts: Harvard University Press.

Bronfenbrenner, U. (1989). Ecological Systems Theory. In R. Vasta \& A. Arbor (Eds.), Six Theories of Child Development: Revised Forumulatoins and Current Issues. Michigan: Jai Press.

Bumpus, M. F. \& Rodgers, K. B. (2009). Parental Knowledge and Its Sources. Journal of Family Issues, 30(10), 1356-1378.

Burdette, A. M. \& Terrence D. (2009). Religious Involvement and Transitions into Adolescent Sexual Activities. Sociology of Religion, 70(1), 28-48.

Chamratrithirong, A., Kittisuksathit, S., Podhisita, C., Isarabhakdi, P. \& Sunpuwan, M. (2007). National Sexual Behavior Survey of Thailand 2006. Thailand: Institute for Population and Social Research, Mahidol University. 
Chamratrithirong, A., Brenda, A., Miller, H. F., Byrnes, O. R., Pamela, K., Cupp, M. J., ... Warunee, C. (2010). Spirituality within the Family and the Prevention of Health Risk Behavior among Adolescents in Bangkok, Thailand. Social Science and Medicine, 71(10), 1855-1863.

Cvetkovich, G. \& Grote, B. (1980). Psychological Development and the Social Problem of Teenage Pregnancy. In C. Chilman (Eds.), Adolescent Pregnancy and Childbearing: Findings from Research (pp. 15-41). Washington, D.C.: U.S. Department of Health and Human Services.

Fordham, G. (1995). Whisky, Women, and Song: Men, Alcohol and Aids in Northern Thailand. The Australian Journal of Anthropology, 6(3).

Jaccard, J. \& Kittus, P. J. (2000). Adolescent Perceptions of Maternal Approval of Birth Control and Sexual Risk Behavior. American Journal of Public Health, 90, 1426-1430.

Jessor, R. (1991). Risk Behavior in Adolescence: A Psychosocial Framework for Understanding and Action. Journal of Adolescent Health. 19-34.

Keenan, P. J. (2008). Do Norms Still Matter? The Corrosive Effects of Globalization on the Vitality of Norms. Vanderbilt Journal of Transnational Law, 41(2), 327-379.

Kinsman, S. B., Romer, D., Furstenberg, F. F. \& Schwarz, D. F. (1998). Early Sexual Initiation: The Role of Peer Norms. US National Library of Medicine, 102(5).

Knodel, J., VanLandingham, M., Chanpen, S. \& Anthony, P. (1996). Thai Views of Sexuality and Sexual Behaviour. Health Transitions Review, 6179-6201.

Knodel, J., Chanpen, S., VanLandingham, M., \& Lucas. R. (1999). Sexuality, Sexual Experience, and the Good Spouse: Views of Married Thai Men and Women. In P. A. C. Jackson \& M. Nerida (Eds.), Genders \& Sexualities in Modern Thailand (pp. 93-113). Thailand: Silkworm Books.

Lyttleton, C. (1999). Changing the Rules: Shifting Bounds of Adolescent Sexuality in Northeast Thailand. In P. A. C. Jackson \& M. Nerida (Eds.), Genders \& Sexualities in Modern Thailand (pp. 28-42). Thailand: Silkworm Books.

MacQueen, K., Taweesak, N., Michael, D. S., Sawangdee, Y., Timothy, D. M. \& Bruce, G. W. (1996). Alcohol Consumption, Brothel Attendance, and Condom Use: Normative Expectations among Thai Military Conscripts. Medical Anthropology Quarterly, 10(3), 402-423.

Maxwell, K. A. (2002). Friends: The Role of Peer Influence across Adolescent Risk Behaviors. Journal of Youth and Adolescence, 31(4), 267-277.

Meschke, L. L., Bartholomae, S. \& Zentall, S. R. (2002). Adolescent Sexuality and Parent-Adolescent Processes: Promoting Healthy Teen Choices. Society for Adolescent Medicine.

Miller, B. C., Benson B., \& Galbraith, K. A. (2001). Family Relationships and Adolescent Pregnancy Risk: A Reearch Synthesis. Developmental Review, 21, 1-38.

Ounjit, W. (2011). Pre-Marital Sex and Pregnancy: The High Price of Forgiveness. International Journal of Social Science and Humanity, 1(2), 111-120.

Phuengsamran, D., Chamratrithirong, A., Guest, P. \& VanLandingham, M. (2014). Rural-Urban Migration and Sexual Initiation of Never-married Young Adults from Kanchanaburi, Thailand. 22(1), 70-86.

Podhisita, C., Xenos, P. \& Varangrat, A. (2001). The Risk of Premarital Sex among Thai Youth: Individual and Family Influences. East-West Center Working Papers, 108(5), 1-25.

Podhisita, C. (2009). Parenting Process and Peer Influence in the Context of Sexual Risk Behavior among Young Adults. In A. Chamratrithirong \& D. Phuengsamran (Eds.) The Era of Arv in the Generalised Hiv Epidemic in Thailand: Research Approaches. Nakorn Pathom: Institute for Population and Social Research, Mahidol University.

Rhuchareonpornpanich, O., Chamratrithirong, A., Warunee, F., Brenda, M., Pamela, K. C., Michael J. R., ... \& Warunee, C. (2012). Parent-Teen Communication About Sex in Urban Thai Families. Journal of Health Communication, 17(4), 380-396.

Singh, S., Deirdre, W., Renee, S., \& Yvette, C. (2000). Gender Differences in the Time of First Intercourse: Data from 14 Countries. International Family Planning Perspectives, 26(1), 21-28 \& 43.

Sridawruang, C., Kenda, C., \& Michael, P. (2010). Attitudes of Adolescents and Parents Towards Premarital Sex in Rural Thailand: A Qualitative Exploration. Sexual \& Reproductive Healthcare, 1,181-1,187.

Sridawruang, C., Michael, P., \& Kenda, C. (2010). Why Thai Parents Do Not Discuss Sex with Their Children: A Qualitative Study. Nursing and Health Sciences, 12, 437-443.

Stattin, H., \& Kerr, M. (2000). Parental Monitoring: A Reinterpretation. Child Development, 71(4), 10721085. 
Tangmunkongvorakul, A., Roslyn, K., \& Kaye, W. (2005). Gender Double Standards in Young People Attending Sexual Health Services in Northern Thailand. Culture, Health \& Sexuality, 7(4), 361-73.

Thianthai, C. (2004). Gender and Class Differences in Young People's Sexuality and Hiv/ Aids RiskTaking Behaviours in Thailand. Culture, Health \& Sexuality, 6(3), 189-203.

United Nations Fund for Population Activities. (2013). Motherhood in Childhood: Facing the Challenge of Adolescent Pregnancy. Bangkok, Thailand: United Nations Population Fund Thailand Country Office.

VanLandingham, M., Somboon, S., Werasit, S., Chayan, V., \& Nancy, G. (1993). Sexual Activity among Never-Married Men in Northern Thailand. Demography, 30(3), 297-313.

VanLandingham, M., \& Nancy, G. (1997). Some Cultural Underpinnings of Male Sexual Behaior Patterns in Thailand. In G. Herdt (eds.), Sexual Cultures and Migration in the Era of Aids (pp. 127142). Oxford: Clarendon Press. 